\title{
Analysis of Machining Pit by using Electrical Discharge Machine Die Sinking
}

\author{
Md Razak Daud ${ }^{l}$, Wan Nor Shela Ezwane Wan Jusoh ${ }^{1}$, Syahrullail Samion ${ }^{2}$ \\ ${ }^{1}$ Mechanical Department, Politeknik Tuanku Sultanah Bahiyah, 09000 Kulim, Kedah \\ ${ }^{2}$ Mechanical Department, Universiti Teknologi Malaysia, 81310 Johor Bahru, Johor, MALAYSIA
}

\begin{abstract}
This study investigates metal removal rate (MRR) of the biomaterial by using discharge machine Neuar CNC A50 Electrical Discharge Machine Die Sinking (EDM DS). The purpose of this study is to compare machining curvature cup for material SKD 11 and stainless steel with shape curvature cup acetabular. The result showed that electrode wear is higher when high current is applied. For each applied current $0.5 \mathrm{~A}$ and 3.0A could result electrode wear of $0.236 \mathrm{~mm}, 0.246 \mathrm{~mm}$ and $0.269 \mathrm{~mm}$ respectively. Mean time of complete discharged for each pit with $0.3 \mathrm{~mm}$ depth with supply $0.5 \mathrm{~A}$ is 6.51 minutes; $1.5 \mathrm{~A}$ is 3.54 minutes and $3 \mathrm{~A}$ is 1.52 minutes. The biggest mean parameter of the pit is $0.356 \mathrm{~mm}$, with $3 \mathrm{~A}$ of current is applied. From this study, it can be concluded that low current set may give lower electrode copper wear. The experiment will help a researcher to discharge biomaterial types of metal with small size of copper electrode use of EDM DS Neuar for discharge multi hole or micro pit.
\end{abstract}

\section{Key words: Electrode Wear, Electrical Discharge Machine Die Sinking, Pit}

\section{INTRODUCTION}

Electro-Discharge Machining (EDM) is a metal removal process by means of electrical energy released by spark discharges occurred between an electrode and the workpiece with electrical conductivity to produce a desired -shaped. It is also known as spark erosion, which is a non-traditional machining method of removing metal by use of recurrent sparks applied to a hard metal or alloy. During discharge a black layer characterization and electrode wear ratio in electrical discharge machining (EDM) will be found [1]. The main cause of wear decrease in the tool according to the set of EDM input parameters used.

EDM is currently applied across fields that require mastery and fineness that conventional tools cannot produce. It also have been found by [2] [3] that high speed processing provides a superior surface finish quality of the conventional Die-cutting. Nowadays EDM die sinker EDM is used for the precision machining of medical parts, aerospace parts, and other highly specialized products. The Die-sinker EDM is widely used machine for machining of hard material with high precision, high surface finish, complex profiles[4]. EDM also has advantages which it can reduce environment pollution than electrochemical machining, ECM. However, it requires higher amount of energy. This study is to achieve micro pits depth $0.3 \mathrm{~mm}$ on the surface of acetabular. Table 1 below shows the parameter of EDM Die-Sinking Ne-uar CNCA50. 
Table 1: Parameters of EDM Die-Sinking Ne-uar CNC-A50

\begin{tabular}{|l|c|}
\hline \multicolumn{1}{|c|}{ SPECIFICATION } & CNC - A50 \\
\hline Work Tank Dimensions & $940 \times 550 \times 350 \mathrm{~mm}$ \\
\hline Work Table Dimensions & $630 \times 360 \mathrm{~mm}$ \\
\hline Distance Between Main Axis To Table & $410 \mathrm{~mm}$ \\
\hline X, Y, Z Axis Travel Dimensions & $400 \times 300 \times 300 \mathrm{~mm}$ \\
\hline Auxiliary Travel Of Z Axis & $500 \mathrm{kgs}$ \\
\hline Max. Workpiece Weight & $50 \mathrm{kgs}$ \\
\hline Max. Electrode Weight & $300 \mathrm{liters}$ \\
\hline Max. Capacity Of Dielectric & $420 \mathrm{~mm}^{3} / \mathrm{min}$ \\
\hline Max. Machining Speed & $<0.1 \%$ \\
\hline Min. Wear Rate & $<$ Ra $0.12 \mu \mathrm{m}$ \\
\hline The Best Surface Finish & $50 \mathrm{~A}$ \\
\hline Max. Output Current & $3.3 \mathrm{KVA}$ \\
\hline Input Power & $155 \times 140 \times 225 \mathrm{~cm}$ \\
\hline Machine Lx W x H & $1370 \mathrm{kgs}$ \\
\hline Total Weight Of Machine Unit & \\
\hline
\end{tabular}

The need of pits in the surface of acetabular is to trap lubricant in the pit and will make the surface of acetabular can move smoothly. Also, will prolong life span of the hip implant. This forward surface inner acetabular is new looking technology in hip implant where is the surface needed to be modified. This study to machine pit on biomaterial as workpieces with shape of acetabular cup using Electrical Discharge Machine EDM DS Neuar CNC A-50.

\section{EXPERIMENT SETUP AND RESULT}

\subsection{Copper as electrode}

The properties of copper electrode materials are made as well as applications recommendations. The metal is closely related with silver and gold, with many properties being shared among these metals. Modern life has a number of applications for copper, ranging from coins to pigments, and demand for the metal remains high, especially in industrialized nations.

In previous researches, cooper as electrode are commonly used[5][6][7][8]. Copper is also commonly used for tubing for certain brands of high speed small hole machines[9][10].In other copper electrodes are preferred material for all high speed small hole applications involving aerospace alloys as well as Carbide .

\subsection{Acetabular as work piece}

An acetabular is made from material metal, which is design as model for hip implant in medical surgery. This material and shape of workpieces based on curvature cup or acetabular. Figure 1 showed the element identification of metal used.

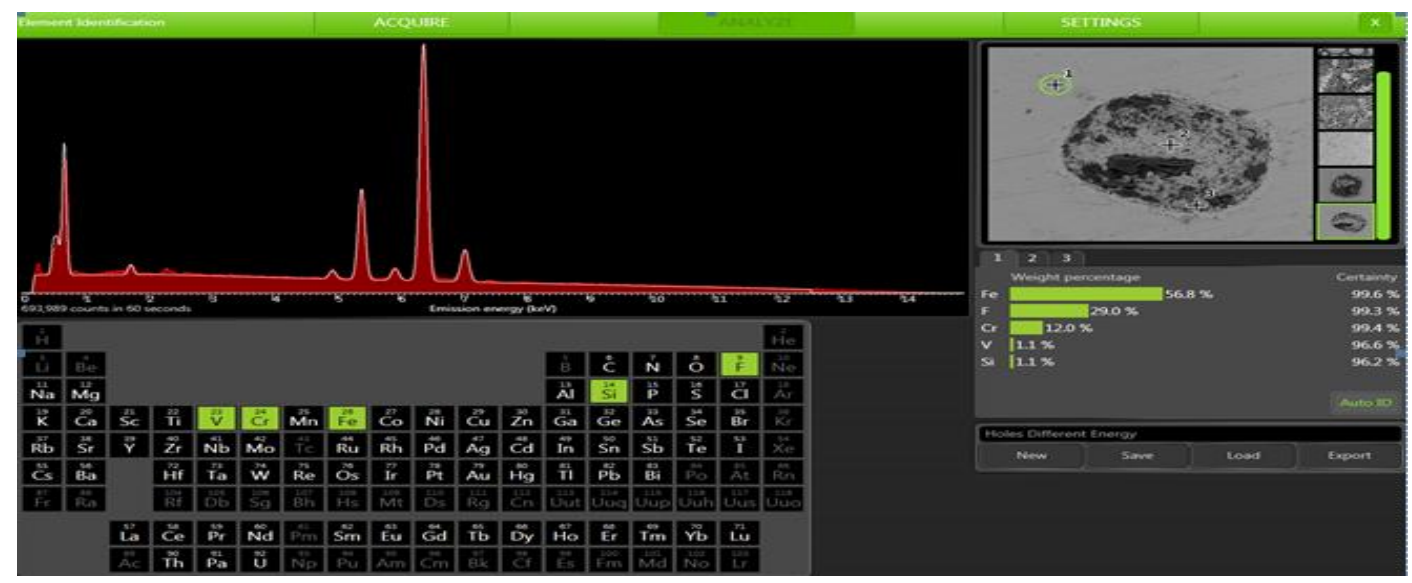


Figure 1: Element identification of SKD 11

\subsection{EDM setting}

The use of oil injection pipe and the position of copper electrode during discharge acetabular are shown in Figure 2. Three different current settings were used $0.5 \mathrm{~A}$ and $3.0 \mathrm{~A}$. The stage of current $(0.5 \mathrm{~A}-3 \mathrm{~A})$ work under low voltage current setting. It is suitable for small and fine tune machining. By set value of $\mathrm{P}_{\mathrm{ON}}$ and $\mathrm{P}_{\mathrm{OFF}}$ are related to the dissipation on copper electrode will reach the finest coarseness of surface. $60 \mathrm{~V}$ positive gap voltage adjustment at bottom discharge set is suitable for discharge small holes or micro pits.

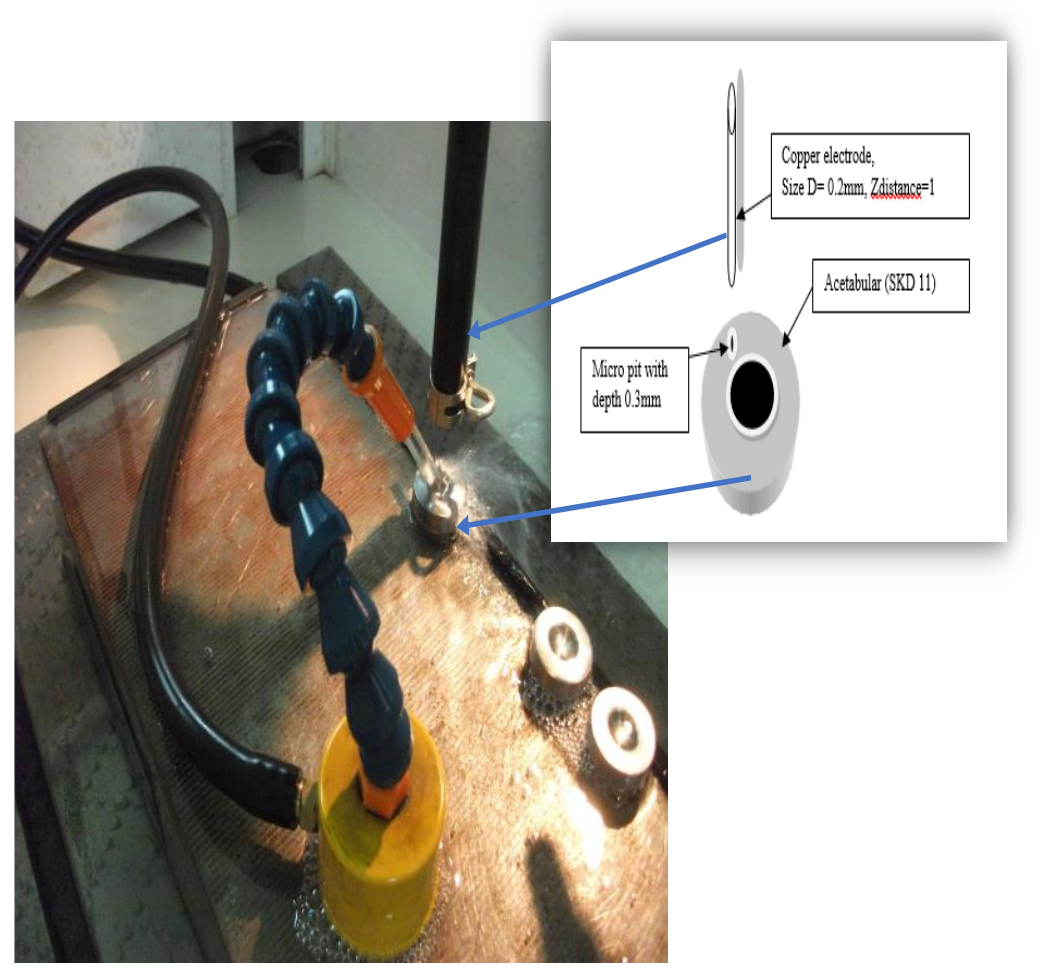

Figure 2: Position of copper electrode during discharge acetabular

\section{RESULT ANALYSIS AND DISCUSSION}

DOE provides a method to simultaneously investigate the effects of multiple variables on an output variable (response).These research have been conducted with three different current settings which are $0.5 \mathrm{~A}$ and 3.0A respectively. This currents setting is set as the main variable and data are collected for every experimental run. By using DOE, it is easier to identify the sequence of experiments or conditions, analyze the data and then determine the input variable (factor).
Based on Table 4.1 shows data *, there are three places. Individually, it can be said the shortest pit hole of a workpiece the material biomaterials with a time of 1.11 minutes and $3 \mathrm{~A}$ current, Vgap at $55 \mathrm{~V}$ (stainless steel). Electrode wear recorded at the lower rate of $1.6 \%$ during to machine pit on LT and Vgap (3A, 55V) respectively, for the stainless steel . However, the success of the workpiece machined the pit by following the actual depth achieved at the highest rate, $96.0 \%$ in the titanium the material with a relatively low electrode wear. Overall, it can be said Electrode wear is below 10 $\%$ and more than 50\% success of EDM DS machine produced the micro pit on the biomaterial. 
Md Razak Daud \& et al./ Journal of Engineering and Science Research, 2(6) 2018, Pages: 63-37

Table 2: Result of experimental

\begin{tabular}{|c|c|c|c|c|c|}
\hline $\begin{array}{c}\text { LT } \\
\text { (A) }\end{array}$ & $\begin{array}{c}\text { Vgap } \\
(\mathrm{V})\end{array}$ & $\begin{array}{c}\text { Material } \\
\text { 1.Titanium } \\
\text { 2Stainlesg steel. }\end{array}$ & \% Electrode wear & Depth archive (\%) & Time of machine (Minute) \\
\hline 0.5 & $\mathbf{5 5}$ & 1 & 8.1 & & \\
\hline 0.5 & $\mathbf{5 5}$ & 1 & 10.5 & 71.7 & 4.25 \\
\hline 0.5 & 65 & 2 & 9.6 & 63.0 & 11.39 \\
\hline 0.5 & 65 & 2 & 10.3 & 64.7 & 4.41 \\
\hline 3 & 55 & 2 & 7.2 & 94.7 & 11.50 \\
\hline 3 & 55 & 2 & $1.6^{*}$ & 91.7 & $1.11^{*}$ \\
\hline 3 & 65 & 1 & 7.1 & 77.0 & 1.54 \\
\hline 3 & 65 & 1 & 1.8 & $96.0^{*}$ & 1.16 \\
\hline
\end{tabular}

In this research, MINITAB software for statistical analysis was used to get regression equations .It shows a regression equation helps us to identify the relation between to parameter Electrode wear(\%),Time of machining and depth of pit archive and influenced the input parameters (current and voltage gap). The MINITAB required the input conditions and the observations of the experiments and developed the regression equations for each parameter demand. Based on the experimental runs, following Regression Equations are obtained:

Electrode wear $(\%)=8.6-2.08 L T(A)+0.035 \mathrm{Vgap}(V)$ (4)

Time of machine $($ Minute $)=8.7-2.62 L T(A)+0.008$ $\operatorname{Vgap}(V) \quad(5)$
Depth archive $(\%)=87.2+9.37 L T(A)-0.425$

$\operatorname{Vgap}(V)$

(6)

From the regression equation researcher will conduct an experiment by prediction values of electrode wear, machining times and depth will archive using EDM DS.In other, the analysis shows the mean and analysis of signal to noise $(\mathrm{S} / \mathrm{N})$. The capability of the EDM DS machining refers to the size of the pit radius produced, which is resembles as an electrode. In this experiment, the Taguchi analysis was used to optimize the robustness of process machining pit. Besides, Design of Experiments (DOE) is used to investigate the effects of current rate varying output size of surface workpieces. Data are collected at each run as given in Table 3.

Table 3. Design of experimental statistic result

\begin{tabular}{cccccc}
\hline StdOrder & RunOrder & Current (A) & Experiment (Run) & inner (mm) & outliner (mm) \\
\hline $\mathbf{1}$ & 1 & 0.5 & 1 & 0.1 & 0.5 \\
$\mathbf{2}$ & 2 & 0.5 & 2 & 0.1 & 0.5 \\
$\mathbf{3}$ & 3 & 0.5 & 3 & 0.1 & 0.5 \\
$\mathbf{4}$ & 4 & 1.5 & 1 & 0.1 & 0.5 \\
$\mathbf{5}$ & 5 & 1.5 & 2 & 0.1 & 0.5 \\
$\mathbf{6}$ & 6 & 1.5 & 3 & 0.1 & 0.5 \\
$\mathbf{7}$ & 7 & 3 & 1 & 0.6 & 0.8 \\
$\mathbf{8}$ & 8 & 3 & 2 & 0.5 & 0.8 \\
$\mathbf{9}$ & 9 & 3 & 3 & 0.5 & 1.0 \\
\hline
\end{tabular}


This research shows a significant relationship between the independent variable (current rates) and the response of experimental (radius of workpieces) which is the inner and outliner radius. The value of $R^{2}$ and adjusted $R^{2}$ is over $85 \%$ showed that current rates is tolerable to predict the response. The $p$-value for the result ANOVA results for radius inner and outliner rate are 0.000 and 0.001 respectively, where (i.e. $\alpha=0.05$, or $95 \%$ confidence) indicates that the experimental model is considered to be statistically significant.

\section{CONCLUSION}

Recently, rapid growth in biomedical engineering technologies has improved the quality and performance of biomedical equipment and healthcare services. By using EDM machine has a potential to be utilized into machining micro surface roughness in biomedical product as long it is conductive material. The results of study were obtained. It was found that copper may use to discharge model of acetabular to complete pit on the surface roughness tool steel workpiece using EDM machine. In the future study, researcher may use of other electrode and new set for different current, QDUP, QDON, $\mathrm{P}_{\mathrm{ON}}, \mathrm{P}_{\mathrm{OFF}}$ and $\mathrm{V}_{\mathrm{GAP}}$ to get minor wear electrode.

\section{ACKNOWLEDGMENT}

The authors would like to express their thanks to COT PTSB and JPPKK for financial support. Thanks also to the Mechanical Department of PTSB for the laboratory facilities.

\section{REFERENCES}

[1] [1] J. Marafona, "Black layer characterisation and electrode wear ratio in electrical discharge machining (EDM)," Journal of Materials Processing Technology, vol. 184, no. 1-3, pp. 2731, Apr. 2007.

[2] [2] M. A. R. M. J. C. Ms.Shruti, "A Review on Current Research Trends in Die- Sinking Electrical Discharge Machining of Conductive Ceramics," vol. 1, no. 5, pp. 100-104, 2009.

[3] [3] T. T. Aung, "A Study of Surface Roughness caused by Conventional and High Speed Machining in Side Milling Operation."

[4] [4] H. T. Nikhil Kumar, Lalit Kumar and R. Yadav, "C OMPARATIVE S TUDY F OR MRR ON D IE -S INKING," pp. 170-174, 2012.

[5] [5] M. Y. A. and M. M. H. Ahsan Ali Khan, "A STUDY OF ELECTRODE SHAPE CONFIGURATION ON THE PERFORMANCE OF Ahsan Ali Khan, Mohammad Yeakub Ali and Md . Mohafizul Haque," vol. 4, no. 1, pp. 19-23, 2009.

[6] [6] K. I. Popov and D. Nikoli, "Electrochimica Acta The effect of the electrode surface roughness at low level of coarseness on the polarization characteristics of electrochemical processes ivkovi c," vol. 55, pp. 1919-1925, 2010.

[7] [7] R. Kern, "Electrode Material Properties That Effect EDM :," 2008.

[8] [8] N. Beri, S. Maheshwari, C. Sharma, and A. Kumar, "Performance Evaluation of Powder Metallurgy Electrode in Electrical Discharge Machining of AISI D2 Steel Using Taguchi Method,"pp. 576-580, 2008.

[9] [9] M. Kunieda and A. Kameyama, "Study on decreasing tool wear in EDM due to arc spots sliding on electrodes," Precision Engineering, vol. 34, no. 3, pp. 546-553, Jul. 2010.

[10] S. Singh and A. Bhardwaj, "Review to EDM by Using Water and Powder-Mixed Dielectric Fluid," vol. 10, no. 2, pp. 199-230, 2011. 